\title{
Morphological integration and developmental progress during fish ontogeny in two contrasting habitats
}

\author{
Laurence Fischer-Rousseau,a Richard Cloutier,a,* and Miriam Leah Zelditch \\ aLaboratoire de Biologie évolutive, Université du Québec à Rimouski, Rimouski, QC G5L 3A1, Canada \\ ${ }^{b}$ Museum of Paleontology, University of Michigan, Ann Arbor, MI, 48109 USA \\ *Author for correspondence (email: richard_cloutier@uqar.qc.ca)
}

\begin{abstract}
SUMMARY Morphological integration can respond to environmental conditions, a response that may be dynamic through ontogeny. Among fishes, brook charrs (Salvelinus fontinalis) display a trophic polymorphism that makes it a good species for analyzing the ontogeny of morphological integration. To better understand the processes regulating variation and integration, we assess the ontogenetic dynamics of covariances and developmental progress for populations of $S$. fontinalis from two habitats that differ in water velocity; lake and stream. Geometric morphometrics and developmental progress were evaluated on 751 and 198 specimens, respectively. In both habitats, most ossification events occur before the transition from alevin to juvenile. This threshold defines two distinct periods. During the first period representing free-embryos and alevins, there are important
\end{abstract}

shape changes and rapid ossification, integration tends to be relatively low and decreasing and the variance of shape drastically decreases. During the juvenile period, the rate of shape change decreases and the onset of ossification is nearly complete, plus integration increases and shape variance stabilizes. While we find two distinct developmental periods, we nonetheless find a notable stability underlying the ontogenetic dynamics of variability as well as gradual change in the structure of covariation within each habitat. Our results imply that the variability of juvenile body shape does not seem to retain signals of variability determined early in ontogeny and warrants caution in using juvenile as guides to the earlier causes of variability. Overall, this study highlights the difficulty of inferring causes of integration from studies of static covariance.

\section{INTRODUCTION}

Morphological integration refers to the interdependence among traits caused by shared function or developmental origin that is typically measured by the statistical associations among traits (Olson and Miller 1958; Cheverud 1982). The structure of those statistical associations reflects processes that affect some traits but not others. It is the covariance-generating processes that produce patterns of morphological integration. Covariance-generating processes can be altered by mutation, and also by the dynamics of development or environmental factors, with consequent changes in the structure and overall level of integration (Riska 1986; Zelditch 1988; Zelditch and Carmichael 1989; Hallgrímsson et al. 2007). A major objective of ecological and evolutionary developmental biology is to understand the developmental, ecological, and evolutionary processes that structure (co)variability, as these are among the determinants of evolvability (Hendrikse et al. 2007).

Changes in covariance structure have been found from age to age within a single environment, revealing the developmental dynamics of integration (Atchley and Rutledge 1980; Zelditch 1987, 1988; Zelditch and Carmichael 1989; Badyaev and Martin 2000; Ivanović et al. 2005; Young 2006; Zelditch et al. 2006). In the case of rodents, there appears to be a close connection between the dynamics of integration and function: both adult function and adult covariance structure are established shortly before weaning and thereafter are stable (Zelditch 1987, 1988; Willmore et al. 2006; Zelditch et al. 2006). The covariance structure of adult rodent skulls thus reflects processes that occurred before weaning, revealing the signature of preweaning developmental processes. In teleosts, we might also anticipate rapid early modifications in integration because this is when we find rapid changes in many traits, such as those documented for body shape, metabolism, swimming ability, and behavior (van Snik et al. 1997; Gisbert 1999). The particular changes in integration that occur during early development may depend on the environmental demands faced by developing phenotypes, and these demands likely vary across environments.

We might also expect that the structure of covariances would differ between habitats because phenotypic plasticity, induced by contrasting environmental demands, is known to have an impact on covariance structure (Schlichting and Pigliucci 1998). Various lacustrine teleosts exhibit a phenotypic 
and behavioral divergence along a benthic versus limnetic axis (Robinson and Wilson 1994 and references cited therein). This divergence is known to affect integration in juvenile pumpkinseed sunfishes (Lepomis gibbosus) for which benthic and limnetic forms can differ in both magnitude and structure of integration (Parsons and Robinson 2006). This divergence is also reported for lake populations of brook charrs (Salvelinus fontinalis) (Venne and Magnan 1995) and functional demand is one of the factors known to induce differences in morphology (Peres-Neto and Magnan 2004; Proulx and Magnan 2004) and integration (Peres-Neto and Magnan 2004). Peres-Neto and Magnan (2004) reared brook charr and Arctic charr (Salvelinus alpinus) juveniles for a period of 6 months under four water velocities, finding that the level of integration was associated negatively with water velocity in Arctic charr. In the case of brook charr, the highest level of integration was found in fishes reared at medium water velocity. That study, which focused on integration in juvenile specimens, did not address the effect of functional demands earlier during development. The differentiation between alternative phenotypes could take root in the interaction between developmental dynamics of integration and environmental demands. This interaction may have particularly large consequences early in ontogeny, when development is most rapid and functional demands change most dramatically.

To better understand the processes responsible for both ontogenetic changes in covariance structure, and their interaction with ecological factors, we herein examine the ontogenetic dynamics of covariances in yearling brook charr from two habitats that differ in water velocity; lake and stream. How covariances change, either over time or across environments, depends on whether the variation that is introduced and/or preferentially removed is random or not. If random variation were being preferentially eliminated from each population, the covariances would become larger relative to the random variation, leading to an increase in the level of integration without a change in covariance structure. Conversely, if the nonrandom variation were being preferentially eliminated or added from the population, the covariances would change relative to the random variance, leading to a modification in level of integration but most importantly, this would lead to a change in covariance structure. The overall levels of variance and integration only provide some of the information needed to understand the developmental dynamics of integration. Samples similar in overall levels of variance or integration can differ in covariance structure and vice versa. We thus examine both overall levels and structure of (co)variance. We also examine the magnitude of changes that occur from size to size as this could affect the amount of variance being newly introduced or the rate at which it is eliminated.

Our analysis of shape change, variance, and integration is placed in a developmental context by measuring developmental progress by the number of newly ossified endoskeletal elements of the pectoral and median fins. These newly ossified endoskeletal elements are of special interest because ossification accurately describes phases of brook charr development (Balon 1980) and can serve as an estimator of developmental rate. Thus the first objective of this study is to examine integration within a single environment, to determine whether covariance structure is stable through posthatch ontogeny. The second objective of this study is to compare the dynamics of covariances during posthatch ontogeny between lake and stream brook charr populations.

\section{MATERIALS AND METHODS}

\section{Sample}

Wild-caught brook charr (S. fontinalis) yearlings were sampled from two separate sites located in the Matapedia Valley, eastern Québec, Canada. The first site, North Gunn Creek, is a tributary of the Causapscal River $\left(48^{\circ} 32^{\prime} \mathrm{N}, 67^{\circ} 07^{\prime} \mathrm{W}\right)$. The second study site, Casault Lake $\left(48^{\circ} 29^{\prime} \mathrm{N}, 67^{\circ} 09^{\prime} \mathrm{W}\right.$; $\left.414 \mathrm{ha}\right)$ is emptying into the Causapscal River; sampling was restricted to the littoral zone. Both Casault Lake and Gunn Creek are connected to the Causapscal River (approximate distance of $14 \mathrm{~km}$ ). Casault Lake will be referred to as "lake" while Gunn Creek will be referred to as "stream." Data collection started May 18, 2005 in the lake habitat and May 23, 2005 in the stream habitat and ended July 21, 2005 at both sites. Sampling was carried out daily before June 21 (10 specimens per day) and at weekly intervals thereafter ( 25 specimens per week) in both habitats. Specimens were euthanized (saturated carbon dioxide solution), fixed in 5\% neutral buffered formaldehyde for $48 \mathrm{~h}$ and conserved in $70 \%$ ethanol.

Immediately following each capture, the site was marked and a multiparameter sampling system $\left(150 \mathrm{MDS}, 600 \mathrm{QS}\right.$ YSI ${ }^{\circledR}$, Yellow Spring, OH, USA) was used for measurement of temperature $\left({ }^{\circ} \mathrm{C}\right)$, dissolved oxygen $(\mathrm{mg} / \mathrm{l})$, and $\mathrm{pH}$. Water velocities $(\mathrm{cm} / \mathrm{s})$ were measured using a Sontek handheld acoustic Doppler velocimeter (SonTek Handheld FlowTracker ADV, San Diego, CA, USA) which provides reliable and accurate water velocity measurements for low velocity values (e.g., $<3 \mathrm{~cm} / \mathrm{s}$ ).

\section{Ossification sequence}

A total of 198 specimens were cleared and doubled stained with Alcian blue for cartilage and Alizarine Red S for bone (Dingerkus and Uhler 1977). A structure was considered to be cartilaginous when it took up Alcian blue and ossified when a clear periosteum was visible and/or when it took up Alizarine Red S. These specimens were used to validate 5 -mm size classes $(<20,20-25,25-30$, $30-35,35-40$ and $>40 \mathrm{~mm}$ ) in terms of their representation of skeletal development as well as to quantify developmental progress in pectoral and median fins (anal, dorsal, and caudal). Age being unknown for these wild-caught brook charrs, we use standard length (SL) as a proxy for biological time (Adriaens and Verraes 2002). SL was measured using the distance between the tip of snout and posterior end of hypurals landmarks. There were three possible developmental states for each endoskeletal element; 0: absence, 1 : cartilage, and 2: bone. Only the transition between cartilage and 
bone was used because the appearance of cartilage was heavily influenced by the size of smaller specimens, whereas ossification was well represented in our sampling range. Calculations of SL were done in TmorphGen6, part of the integrated morphometrics programs; compiled stand-alone versions running in Windows are freely available electronically at http://www3.canisius.edu/ sheets/ morphsoft.html.

We used a logistic regression to describe the relationship between the continuous predictor variable (SL) and the random component (developmental states for each element) in order to estimate the $\mathrm{SL}$ at a $50 \%$ cutoff point $\left(\mathrm{SL}_{50}\right)$, giving an estimate of the SL at which half of the specimens are ossified for a given element in each habitat. The significance of the logistic regression was tested using the $G^{2}$ statistic, also termed the likelihood ratio $\chi^{2}$-statistics, which is more robust than the Wald $t$ (Quinn and Keough 2002). Out of the 142 elements initially included, only 66 elements (Figs. 3 and 4) for which the logistic model was significant $(P \leq 0.05)$ were considered for analysis of developmental progress. The main effect of habitat was tested using a permutation-paired $t$-test in which $\mathrm{SL}_{50}$ was randomly reassigned 9999 times within each of the 66 elements (block) and for which the $t$ statistic was computed each time. The $P$-value of the two-tailed test is two times the proportion of randomized samples exterior to the $t$-value of the sample. Logistic regression and permutation-paired $t$-test were programmed on Systat (Version 11, Systat Software Inc., Richmond, CA, USA).

\section{Morphometric analysis}

Twelve landmarks (Fig. 1) were digitized on the left side of each individual by the same observer (L. F. R.). Specimens were placed in a custom device, a small transparent plastic box with transverse strings to ensure a constant and horizontal orientation of all fishes. Only specimens with intact fins and minimal body bending were included for a final sample size of 751 individuals (lake, $N=394$; stream, $N=357$ ). Samples were divided into six successive $5-\mathrm{mm}$ size classes (lake, $\quad<20 \mathrm{~mm}, \quad N=70 ; \quad 20-25 \mathrm{~mm}, \quad N=133$; $25-30 \mathrm{~mm}, N=81 ; 30-35 \mathrm{~mm}, N=62 ; 35-40 \mathrm{~mm}, N=34$ and $>40 \mathrm{~mm}, N=14$; stream, $<20 \mathrm{~mm}, N=27 ; 20-25 \mathrm{~mm}, N=72$; 25-30 mm, $N=110 ; 30-35 \mathrm{~mm}, N=69 ; 35-40 \mathrm{~mm}, N=43$ and $>40 \mathrm{~mm}, N=36$ ). Shape analyses were done by superimposing configurations of landmarks using the generalized least squares (GLS) procrustes superimposition, which preserves all information about shape differences among specimens, removing only the information unrelated to shape (i.e., scale, position, and orientation; Rohlf and Slice 1990). Preliminary exploration using principal component analyses (PCA) found that dorsoventral bending of specimens, a preservational artifact (Wund et al. 2008), explained $\mathrm{PC} 1$ and accounted for $>40 \%$ of the variance in each sample. To remove that nonbiological variation from the data, we regressed shape on PC1 scores and analyzed the residuals from that regression (Wund et al. 2008). The resulting PCA shows PC1 to be identical to PC2 in the original data and the ontogenetic component to be unaltered by this manipulation. We similarly removed allometric variation within each size class by analyzing the residuals from a regression of shape on size, measured as centroid size (CS). Landmarks were digitized using tpsDig version 2.10 and tests of allometry were performed using tpsRegr version 1.34., freely avail-

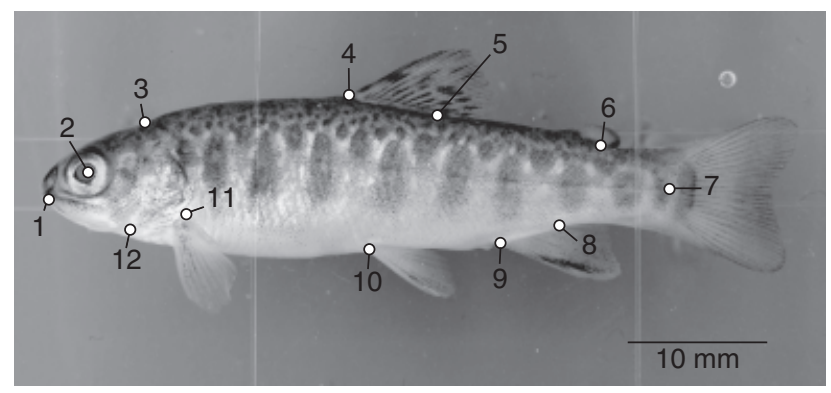

Fig. 1. Twelve biologically relevant landmarks identified on brook charr (Salvelinus fontinalis). 1, Tip of snout; 2 , center of the eye; 3 , posterior limit of skull roof; 4 , anterior insertion of dorsal fin base; 5 , posterior insertion of dorsal fin base; 6 , posterior insertion of adipose fin base; 7, posterior end of hypurals; 8 , posterior insertion of anal fin base; 9 , anterior insertion of anal fin base; 10, pelvic fin insertion; 11, pectoral fin insertion; 12, posterior limit of lower jaw.

able at: http://life.bio.sunysb.edu/ee/rohlf/software.html. GLS superimposition and the calculation of CS were performed in CoordGen6, allometric correction was performed in Standard6 and preliminary PCA were done in PCAGen6; all programs part of the IMP series.

\section{Morphological variation and integration Mean shape}

Mean shapes were generated for each size class and compared using Goodall's F-test (Goodall 1991; Rohlf 2000). To estimate the amount of shape differences between two samples, we calculated the full Procrustes distance between means and statistical significance of the difference in the distances was determined by bootstrapping $(900$ bootstraps). The nature of these shape differences are depicted by vectors of relative landmark displacements on a deformed grid to show the changes between means of successive size classes within each habitat, and across habitat for each size class.

\section{Variance of shape}

To estimate the variance of shape, we used the standard formula for a variance:

$$
V=\frac{\sum_{j=1}^{n} d_{j}^{2}}{(n-1)}
$$

where $d_{j}$ is the Procrustes distance of individual $j$ from the mean shape for its size and $n$ is the sample size for a size class. This distance metric is Euclidean so $V$ is also the trace of the variancecovariance matrix of shape variables (i.e., the sum of their univariate variances) and, in these calculations, it does not matter whether the variances are computed from the shape coordinates or any other geometric shape variables, such as the partial warp scores, because all give the same estimate of the distance. To determine whether size classes or habitats differ in the variance of shape, we used a $t$-test, with standard errors of shape variance estimated by bootstrapping with 999 iterations (calculations were done in Disparity Box6, part of the IMP series). 


\section{Level of integration}

We quantified the level of morphological integration (I) using the variance of eigenvalues (Wagner 1984) extracted from the covariance matrix (Young 2006). The rationale for this metric is that when covariances are high, most of the variance lies along the first few eigenvectors, whereas the remaining eigenvalues are small, producing a large variance in eigenvalues. Conversely, when the variables are nearly independent of each other, all eigenvalues are similar to each other and their variance is low (Wagner 1984). In Wagner (1984), eigenvalue variance was derived from a correlation matrix which makes $I$ directly comparable across populations or species so long as adjustments are made for the number of traits and sample size. In the case of landmark data, the common scale for shape variation is eliminated when correlation matrices are used (Klingenberg and McIntyre 1998), covariance matrices are therefore more appropriate. When $I$ is calculated from the covariance matrix, it depends not only on the number of traits and sample size but also on the variance within the sample, therefore the variance of eigenvalues was standardized by the total shape variance in each sample (the trace of the variance-covariance matrix) (Willmore et al. 2006; Young 2006). Significance of differences in variance of eigenvalues was calculated by bootstrapping each dataset using 999 iterations; to determine the statistical significance of the difference between two samples (successive size classes within each habitat or across habitat for each size class), we used a twotailed test in which the differences were ordered from largest to smallest, and determined whether zero lay within the top and bottom $2.5 \%$. The calculation of variance of standardized eigenvalues and bootstrapping of data matrix were performed in $\mathrm{R}(\mathrm{R}$ Development Core Team 2005).

\section{Structure of integration}

The structure of covariation within each sample was analyzed using PCA. Covariance structures are often compared across populations by common principal components analysis (Flury 1988), but this procedure presupposes that the principal components are well-defined, meaning that the eigenvalues of successive components are statistically distinct. When this is not the case, the variation is more hyperspherical than hyperelliptical and random samples drawn from a single hyperspherical population could yield apparently different PC1s. Thus, apparently large differences between samples could be due simply to chance. To determine whether the first and second eigenvalues of our samples are statistically distinct, we used Anderson's (1963) test for the distinctness of eigenvalues. The null hypothesis of indistinct eigenvalues was rejected for only one sample (20-25 mm lake yearlings).

Therefore, to compare the structure of variation we used common subspace analysis (CSA), another method developed by Flury (1988) for cases in which populations lack distinct eigenvalues. In this approach to comparing covariance structures, the difference between multidimensional subspaces is measured by the minimum angle through which one subspace must be rotated to align it with the other (Flury 1988; Zelditch et al. 2006). This value is then compared with the distribution of angles obtained by drawing two random samples (with replacement) from each dataset. Thus, the angle between the two samples is compared with the distribution of angles obtained within each sample (for technical details, see Zelditch et al. 2006). In our comparisons, we included as many dimensions as needed to account for $80 \%$ of the variance, which is typically from six to eight components. The remaining components are individually trivial, accounting for $<5 \%$ of the variance. PCA were performed using PCAGen6, CSA were performed using SpaceAngle, programs part of the IMP series.

Additionally, covariance matrices were compared using random skewers methods (Cheverud 1996). Random skewers compare the evolutionary responses of each covariance matrix to random selection vectors (Marroig and Cheverud 2001; Ackermann and Cheverud 2002). Details of this method can be found in Cheverud (1996). Briefly, a total of 10,000 random selection vectors were applied to each matrices and their responses compared using the average vector correlation. These average vector correlations can be interpreted like a standard correlation coefficient. They will fall between 0 and 1 , with the extremes indicating inequality and equality in covariance structure, respectively. The statistical significance of this similarity is tested by comparing the observed vector correlation to the distribution of vector correlations between random vectors. If the observed vector correlation exceeds $95 \%$ of those obtained in the randomization, the similarity of the variance/ covariance matrix is significantly greater than zero. Calculations were done using Skewers, a freely available program from L. J. Revell (http://anolis.oeb.harvard.edu/ liam/programs/).

\section{RESULTS}

\section{Ossification sequence}

The majority of ossification events take place before yearlings reach $30 \mathrm{~mm}$ (Figs. 2 and 3). Proximal radials at the center of the dorsal fin (PRD3 to PRD11) and the anal fin (PRA3 to PRA10) ossify before yearlings reach $20 \mathrm{~mm}$. Elements ossifying later, up to $45 \mathrm{~mm}$, include the ones at the margins of the dorsal and anal fins. Proximal radials from left and right pectoral fins ossify when yearlings reach around $25 \mathrm{~mm}$. In the caudal fin, the majority of elements ossify before yearlings reach $20 \mathrm{~mm}$. These include arches, as well as haemal and neural spines of the caudal vertebra, hypurals, epurals, and uroneural 1. Elements of the caudal fin ossifying later include the dorsal and ventral arcocentra, preural centra and ural centra 1 and 2 and uroneural 2. A permutation-paired $t$-test shows ossification events in stream fishes occur at a significantly smaller $\mathrm{SL}_{50}(P=0.0003)$ with a mean difference of $0.719 \mathrm{~mm}$.

In fishes with intermediate development like brook charrs, hatchlings emerge from the egg envelopes as late free-embryos with no functional gills, median fins that are part of the finfold and an axial skeleton that only exists as cartilaginous structures, if at all (Balon 1980). At the transition to exclusive external feeding, these free-embryos become alevins, and finally, when most temporary structures found in embryos and alevins have been replaced by definitive adult organs or structures, the fish is considered a juvenile (Balon 1980). The free-embryo to alevin transition is not clearly visible using ossified skeletal structures but according to Balon (1980), the 

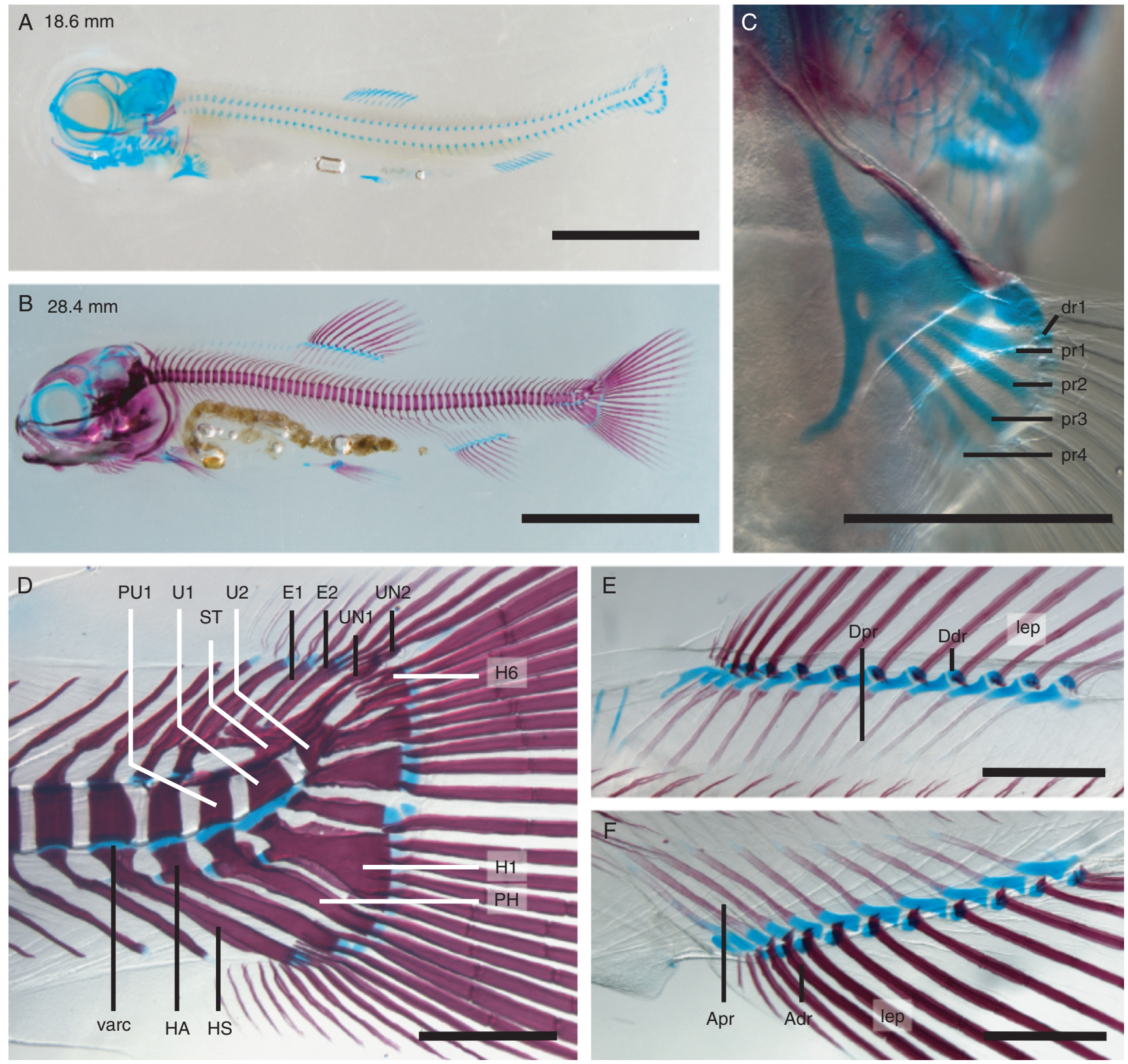

Fig. 2. Cleared and stained brook charr showing cartilage in blue and bone in red. (A) Whole specimen, scale bar $5 \mathrm{~mm}$. (B) Whole specimen, scale bar $10 \mathrm{~mm}$. (C) Pectoral fin, scale bar $1 \mathrm{~mm}$; dr, distal radials; dr, distal radials; pr, proximal radials. (D) Caudal fin, scale bar $1 \mathrm{~mm}$; E1-2, epurals 1-2; HA, haemal arch; HS, haemal spine; H1-6, hypural 1-6; PH, parhypural or haemal spine of preural centrum 1; PU1,. preural centra 1; UN1-2, uroneural 1-2; U1-2, ural centra 1-2; varc, ventral arcocentra. (E) Dorsal fin, scale bar 1 mm; Ddr, dorsal distal radials; Dpr, dorsal proximal radials; lep, lepidotrichia. (F) Anal fin, scale bar $1 \mathrm{~mm}$; Adr, anal distal radials; Apr, anal proximal radials; lep, lepidotrichia.

transition between alevin and juvenile is evidenced by the completion of the ossification of the axial skeleton. Accordingly, the smallest brook charrs (approximately $15 \mathrm{~mm}$ ) can first be identified as late free-embryos and then as alevins, while specimens of more than $25-30 \mathrm{~mm}$ in SL can be considered juveniles.

\section{Morphological variation and integration Mean shape}

Mean shapes differ between successive size classes within each habitat, with the exception of $35-40$ and $>40 \mathrm{~mm}$ in lake, as well as across habitats for each size class (Table 1). In both 


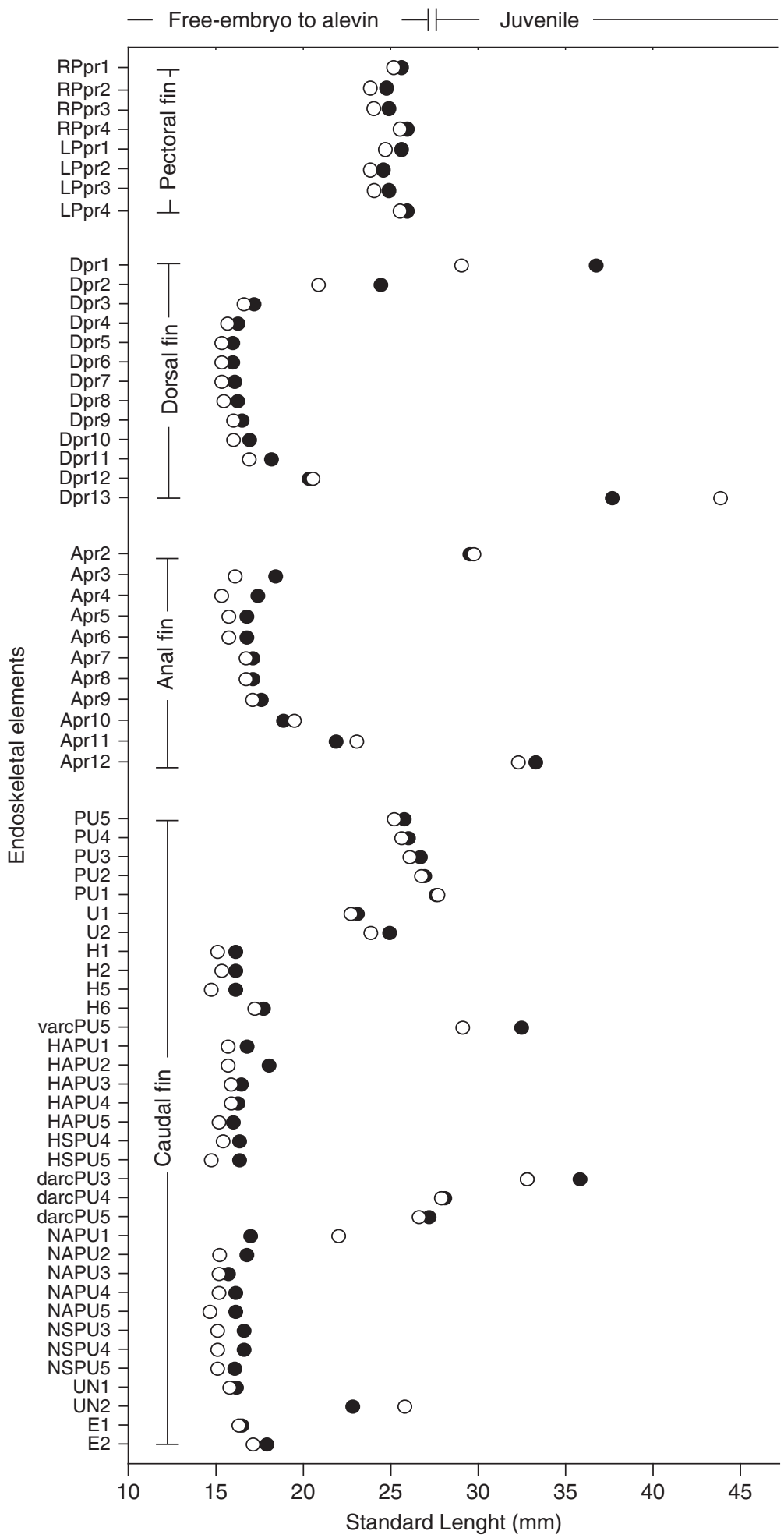

Fig. 3. Standard length at a $50 \%$ cutoff point determined by logistic regression for the pectoral, dorsal, anal, and caudal fins of brook charr yearlings from lake and stream, indicated by filled and empty symbols, respectively. Apr2-12, anal proximal radials 2-12; darcPU3-5, dorsal arcocentra of preural centra 3-5; Dpr113, dorsal proximal radials 1-13; E1-2, epurals 1-2; H1-6, hypurals 1-6; HAPU1-5, haemal arch of preural centra 1-5; HSPU4-5, haemal spine of preural centra 4-5; LPpr 1-4, left pectoral proximal radials 1-4; NAPU1-5, neural arch of preural centra 1-5; NSPU3-5, neural spine of preural centra 3-5; PU1-5, preural centra 1-5; RPpr1-4, right pectoral proximal radials $1-$ 4; U1-2, ural centra 1-2; UN1-2, uroneural 1-2; varcPU1-5, ventral arcocentra of preural centra 1-5. habitats, full Procrustes distances display a similar ontogenetic pattern; amount of shape change is significant except in the case of $35-40$ to $>40 \mathrm{~mm}$ lake samples $(P=0.1383)$ (Table 1). In both habitats, most shape changes (Fig. 4, A and B) seen between the smallest size classes $(<20$ to 20 $25 \mathrm{~mm}$ ) concern an increase in head and trunk depths. This increase in depth is complemented by a remodeling of caudal peduncle proportions (forward migration of the dorsal fin as 
Table 1. Procrustes distances between mean shapes, statistical significance of the differences in mean shapes (Goodall's $F$-test) and distance between means (Bootstrap estimate): (A) for successive size classes within each habitat, (B) across habitat for each size classes

\begin{tabular}{lccccccc}
\hline & \multicolumn{3}{c}{ Lake } & & \multicolumn{2}{c}{ Stream } \\
\cline { 2 - 3 } & Distance & Goodall's $F$ & Bootstrap estimate & & Distance & Goodall's $F$ & Bootstrap estimate \\
\hline (A) & & & & & & \\
$<20$ to $20-25 \mathrm{~mm}$ & 0.014 & 0.000 & 0.001 & & 0.018 & 0.000 & 0.001 \\
$20-25$ to $25-30 \mathrm{~mm}$ & 0.015 & 0.000 & 0.001 & & 0.019 & 0.000 & 0.001 \\
$25-30$ to $30-35 \mathrm{~mm}$ & 0.013 & 0.000 & 0.001 & & 0.013 & 0.000 & 0.001 \\
$30-35$ to $35-40 \mathrm{~mm}$ & 0.017 & 0.000 & 0.001 & & 0.014 & 0.000 & 0.001 \\
$35-40$ to $>40 \mathrm{~mm}$ & 0.009 & 0.138 & 0.216 & & 0.008 & 0.002 & 0.023 \\
\hline
\end{tabular}

\begin{tabular}{lccc}
\hline Lake versus stream & Distance & Goodall's & Bootstrap estimate \\
\hline$(B)$ & & & \\
$<20 \mathrm{~mm}$ & 0.015 & 0.000 & 0.001 \\
$20-25 \mathrm{~mm}$ & 0.011 & 0.000 & 0.001 \\
$25-30 \mathrm{~mm}$ & 0.015 & 0.000 & 0.001 \\
$30-35 \mathrm{~mm}$ & 0.019 & 0.000 & 0.001 \\
$35-40 \mathrm{~mm}$ & 0.023 & 0.000 & 0.001 \\
$>40 \mathrm{~mm}$ & 0.023 & 0.000 & 0.001 \\
\hline
\end{tabular}

well as contraction of the space between the adipose fin and the posterior end of hypurals landmarks) in larger size classes (20-25 to $35-40 \mathrm{~mm})$. Shape changes are generally congruent between habitats but seem to be initiating at a smaller size in stream. For example, the marked increase in depth is already visible between $<20$ and $20-25 \mathrm{~mm}$ in stream, whereas it is most noticeable between $20-25$ and $25-30 \mathrm{~mm}$ in lake. Regarding shape differences between lake and stream, Fig. 4C shows that from the smallest size class, differences concern mostly the caudal peduncle which is shorter (contraction of the space between the adipose fin and the posterior end of hypurals landmarks) in relation to the rest of the body in stream fishes. As fishes increase in size, differences also include body depth and median fins (dorsal and anal); overall, stream fishes develop a deeper body with longer dorsal and anal fin bases and a more compressed caudal peduncle.

\section{Variance of shape}

In both habitats, variance is approximately halved between the $<20 \mathrm{~mm}$ size class and $35 \mathrm{~mm}$ yearlings, a decrease that is statistically significant (Fig. 5A). After that point, variance is statistically constant. In the comparison between habitats, only one size class $(25-30 \mathrm{~mm})$ differs statistically significantly: the variance within that class is significantly greater in the lake habitat.

\section{Level of integration}

In both habitats, integration decreases early in ontogeny. In the lake habitat, this decrease continues to the $25-\mathrm{mm}$ size class; in the stream habitat it continues to the $30-\mathrm{mm}$ size class (Fig. 5B; Table 2). There is a tendency for increasing integration later in ontogeny even though differences between consecutive size classes are not always significant (Table 2).

The comparison between the two habitats shows that at medium sizes, fish from the lake habitat are more highly integrated than the ones from the stream habitat (i.e., 20-25, $25-30$, and $30-35 \mathrm{~mm}$ ) whereas the level of integration in larger size classes does not differ significantly between habitats (Fig. 5B; Table 2).

\section{Structure of variation}

PCA reveals that in most size classes of both habitats, the most highly variable feature is body depth relative to body length, variation that is visually evident in the contrasting displacements of landmarks at the anterior and posterior insertions of the dorsal fin versus pelvic fin (Fig. 6, A and B). Another variable feature found at several sizes in both habitats is head size relative to body length; variation that is evident by the contrasting displacement of landmarks at the mouth and pectoral fin insertion. Finally, the third typically variable feature is posterior body proportions, as indicated either by the contrasting displacement of the anterior and posterior dorsal fin base relative to the adipose and caudal 
A

$<20 \mathrm{~mm}$ to $20-25 \mathrm{~mm}$

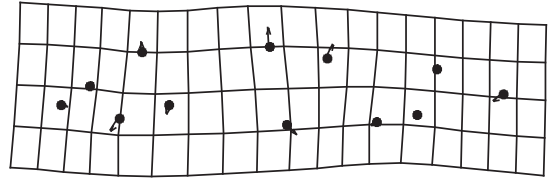

$20-25 \mathrm{~mm}$ to $25-30 \mathrm{~mm}$

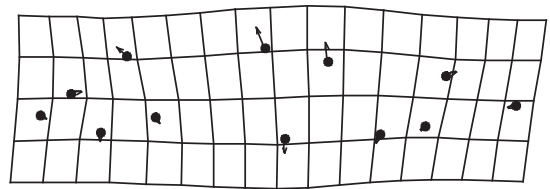

$25-30 \mathrm{~mm}$ to $30-35 \mathrm{~mm}$

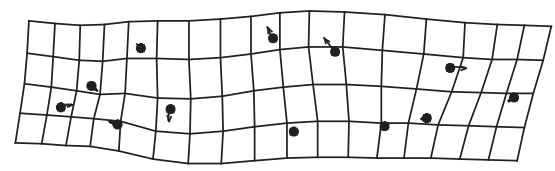

$30-35 \mathrm{~mm}$ to $35-40 \mathrm{~mm}$

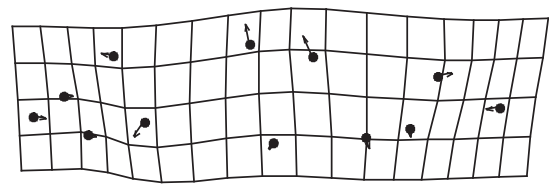

$35-40 \mathrm{~mm}$ to $>40 \mathrm{~mm}$

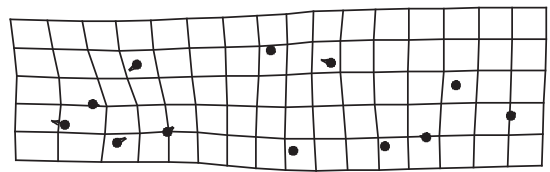

B

$<20 \mathrm{~mm}$ to $20-25 \mathrm{~mm}$

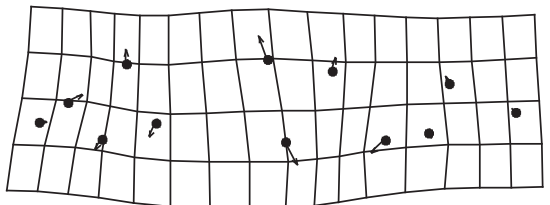

$20-25 \mathrm{~mm}$ to $25-30 \mathrm{~mm}$

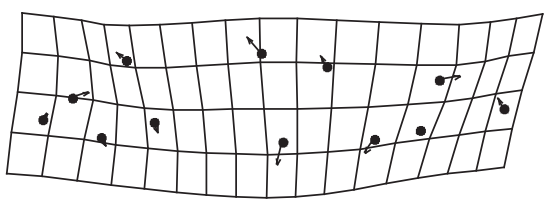

25-30mm to $30-35 \mathrm{~mm}$

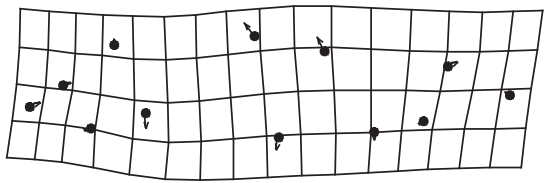

$30-35 \mathrm{~mm}$ to $35-40 \mathrm{~mm}$

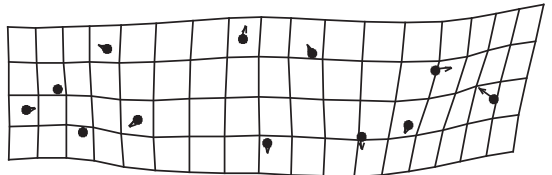

$35-40 \mathrm{~mm}$ to $>40 \mathrm{~mm}$

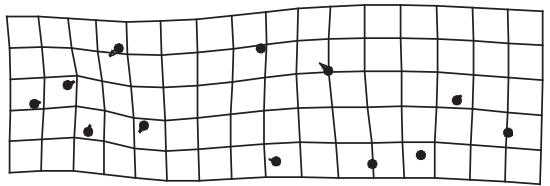

C

$<20 \mathrm{~mm}$

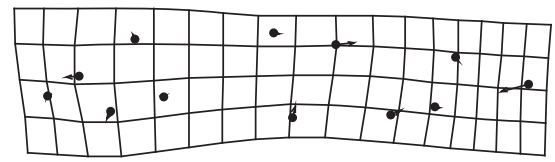

20-25mm

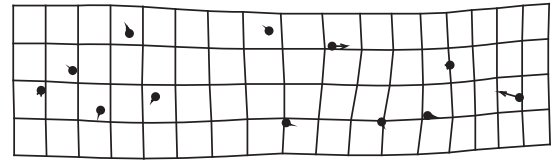

25-30mm

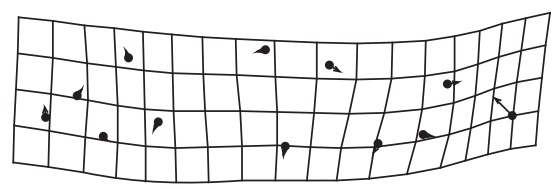

30-35mm

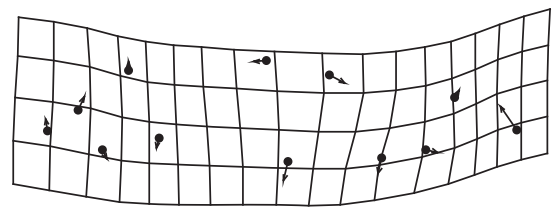

$35-40 \mathrm{~mm}$
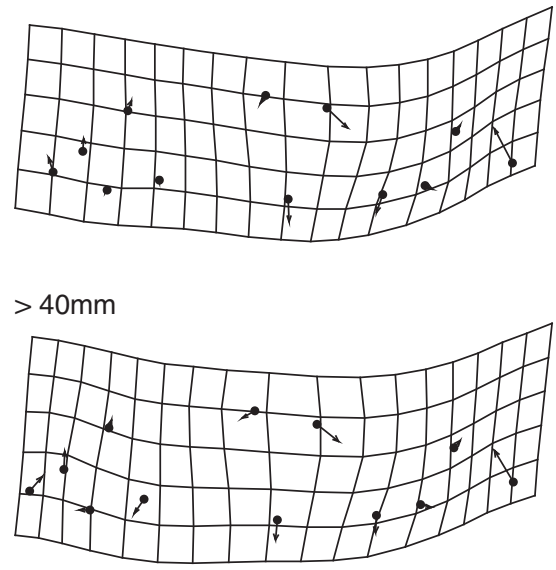

Fig. 4. Ontogenetic changes in mean shape within habitats: (A) lake, (B) stream, and between-habitat differences in mean shape for the same size class: (C) the ontogenetic changes are shown as a deformation of the smaller to the larger mean, the differences between habitats are shown as a deformation of the mean lake to stream shapes. Owing to the subtlety of shape changes between samples, the magnitude of shape changes are exaggerated fivefold.

peduncle, or else by the contrasting displacement of the anterior pelvic fin insertion and caudal fin.

For the majority of size classes in the lake habitat, the three variation patterns described above are easily identifiable but this is not the case for samples from the stream habitat.
Although variation in body depth relative to length is clearly evident in this habitat as well, it is dispersed across several PCs because it is associated with different combinations of other features (Fig. 6B). Among those other features are the landmark at the posterior limit of skull roof and those at the 

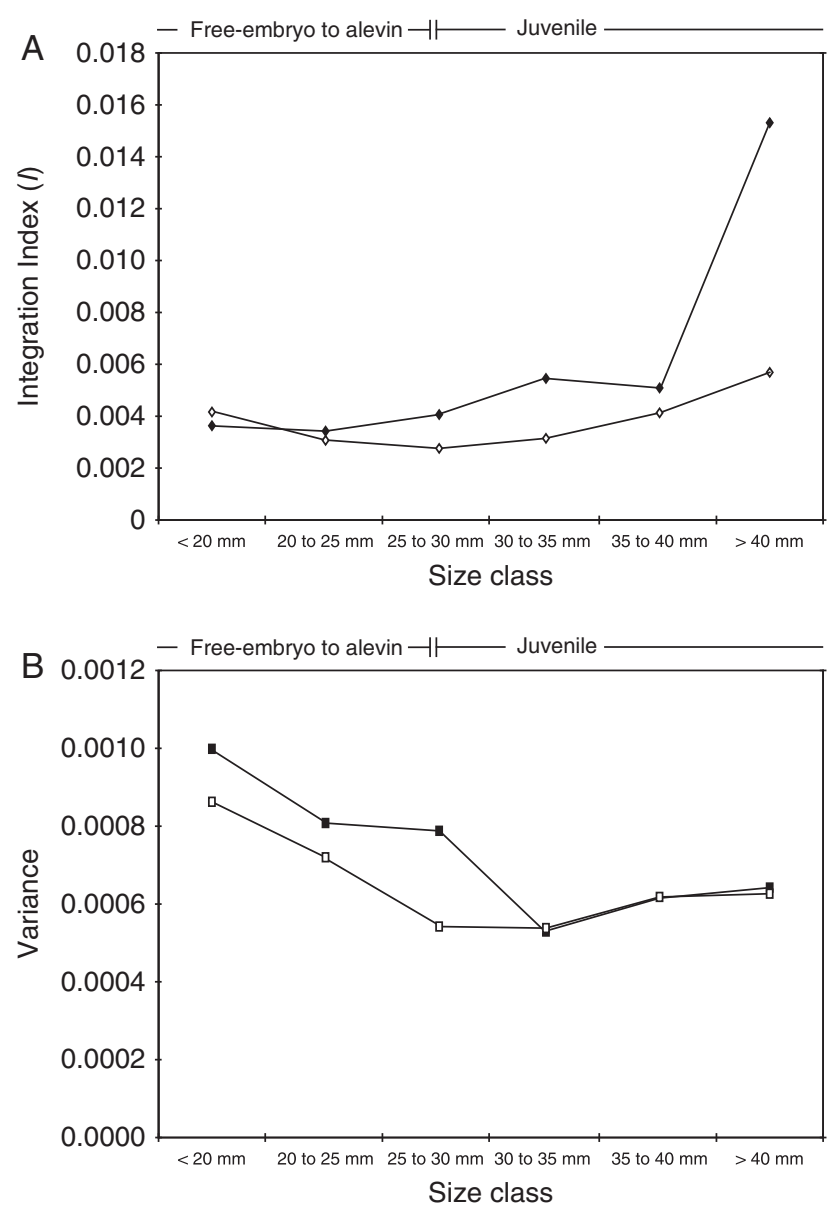

Fig. 5. Index of integration $(I)$ and variance through ontogeny for brook charrs from lake and stream, indicated by filled and empty symbols, respectively. (A) Index of integration (diamond) is estimated by the variance of their standardized eigenvalue from their covariance matrix; (B) variance (square) is the trace of the variance-covariance matrix of shape variables.

pelvic, anal, and adipose fins (representing height of the caudal peduncle). A second aspect of posterior body shape variation that is seen in the stream habitat but not in the lake habitat involves the adipose fin and caudal peduncle.
CSA shows there is a gradual change in structure of covariation throughout ontogeny. Only one comparison reveals a statistically significant difference between successive size classes: $20-25$ versus $25-30 \mathrm{~mm}$ samples from the stream habitat (Table 3A). However, comparisons to the smallest size class $(<20 \mathrm{~mm})$ shows angles between samples are increasing as ontogeny proceeds in both habitats (Table 3B). The structure of covariation differs significantly between the smallest size class and larger ones in both habitats (i.e., 30-35 and $35-40 \mathrm{~mm}$ in lake and $35-40$ and $>40 \mathrm{~mm}$ in stream). The two habitats differ statistically significantly in structure of covariation only at smaller sizes (i.e., $<30 \mathrm{~mm}$ ) (Table 3C).

Average vector correlations between covariance matrices show that samples are more similar than expected by chance (Table 4) as expected from the results of CSA. In no case could we reject the null hypothesis that variance/covariance matrices are no more similar than expected by chance. The correlation coefficients suggest that similarity between ageclasses increases over ontogeny in lake, whereas it decreases in stream (Table 4) but these trends are not statistically significant $(P=0.000)$. Comparisons between habitats also show that covariance structures are moderately similar, least so at the largest sizes, with $P$-values of 0.000 , except between lake and stream for $30-35(P=0.001)$ and $>40 \mathrm{~mm}(P=0.005)$. Overall, these correlations suggest that successive size classes from the same habitat are moderately to highly similar to each other, and those from the same size class from the two habitats are moderately similar to each other.

\section{DISCUSSION}

\section{The transitions between developmental intervals coincide with a shift between periods defined by levels of variance and integration}

During the free-embryo and alevin periods, there are large shape changes (i.e., increase in head and trunk depths, change in caudal peduncle proportions), rapid ossification, and the overall level of integration tends to be relatively low and decreasing, especially in the stream samples. Additionally, the

Table 2. Magnitude of differences in the levels of integration for brook charr yearlings from lake and stream

\begin{tabular}{lrrrrr}
\hline & $<20 \mathrm{~mm}$ & $20-25 \mathrm{~mm}$ & $25-30 \mathrm{~mm}$ & $30-35 \mathrm{~mm}$ & $35-40 \mathrm{~mm}$ \\
\hline$<20 \mathrm{~mm}$ & -0.00053 & $-\mathbf{0 . 0 0 1 0 9}$ & $-\mathbf{0 . 0 0 1 4 0}$ & $-\mathbf{0 . 0 0 1 0 1}$ & $-\mathbf{0 . 0 0 0 0 3}$ \\
$20-25 \mathrm{~mm}$ & $-\mathbf{0 . 0 0 0 2 1}$ & $\mathbf{0 . 0 0 0 3 6}$ & $-\mathbf{0 . 0 0 0 3 1}$ & $\mathbf{0 . 0 0 0 0 8}$ & 0.00106 \\
$25-30 \mathrm{~mm}$ & $\mathbf{0 . 0 0 0 4 3}$ & 0.00064 & $\mathbf{0 . 0 0 1 3 0}$ & 0.00039 & $\mathbf{0 . 0 0 1 5 3}$ \\
$30-35 \mathrm{~mm}$ & $\mathbf{0 . 0 0 1 8 2}$ & $\mathbf{0 . 0 0 2 0 3}$ & $\mathbf{0 . 0 0 1 3 9}$ & $\mathbf{0 . 0 0 2 3 1}$ & 0.00262 \\
$35-40 \mathrm{~mm}$ & $\mathbf{0 . 0 0 1 4 6}$ & $\mathbf{0 . 0 0 1 6 6}$ & $\mathbf{0 . 0 0 1 0 3}$ & -0.00037 & $\mathbf{0 . 0 0 0 9 8}$ \\
$>40 \mathrm{~mm}$ & 0.01168 & 0.01189 & 0.01125 & $\mathbf{0 . 0 0 9 8 6}$ & 0.00096 \\
\hline
\end{tabular}

Differences are indicated for lake size classes in the lower half of the matrix and for stream size classes in the upper half of the matrix, difference between habitats are indicated on the diagonal. The level of integration of the smaller size class is always subtracted from that of the larger one while for between-habitat differences, the level of integration of the stream sample is subtracted from that of the lake sample. Significant differences are indicated by bold face $(P<0.05)$. 


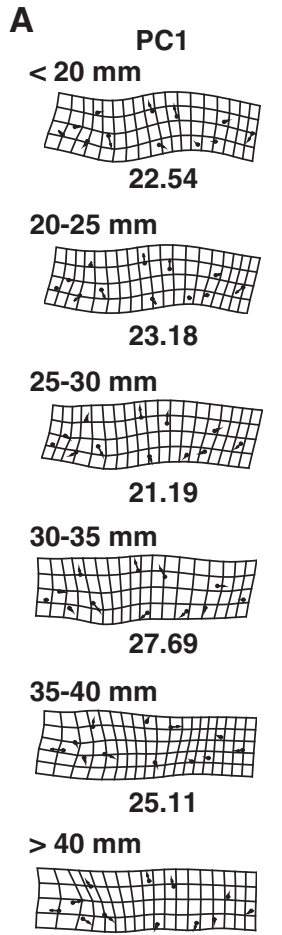

42.89
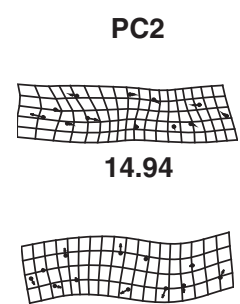

14.03

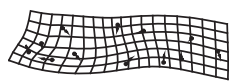

20.82
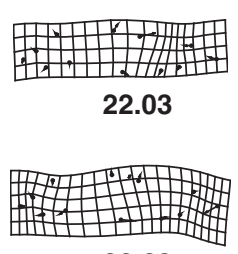

20.63

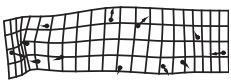

22.87

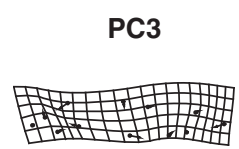

14.45

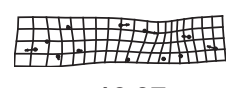

10.97

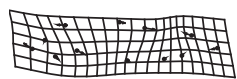

12.20
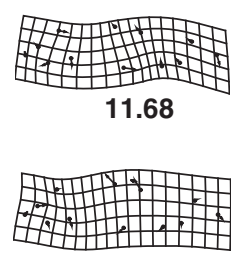

14.14

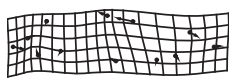

11.23
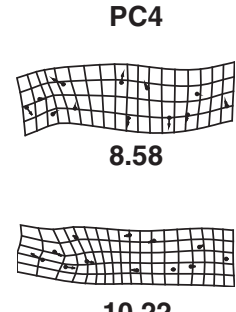

10.22

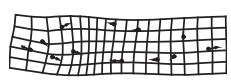

9.48
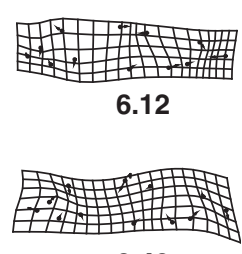

8.49

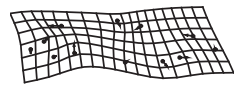

8.40

\section{B $<20 \mathrm{~mm}$ 平册曲 23.02}

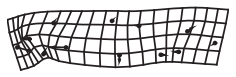

16.44

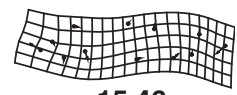

15.46

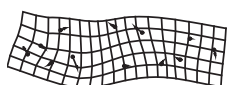

15.75

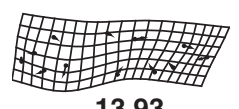

13.93

$35-40 \mathrm{~mm}$

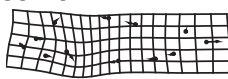

23.30

$>40 \mathrm{~mm}$

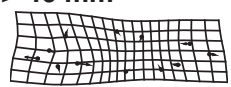

29.41

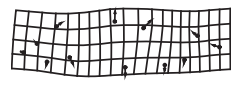

17.22

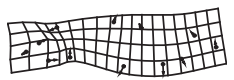

18.92
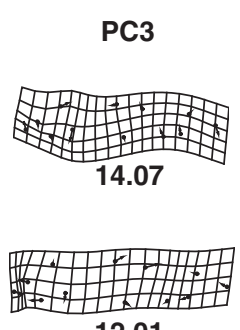

12.01

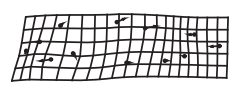

11.33

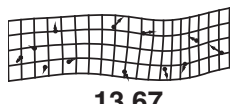

13.67

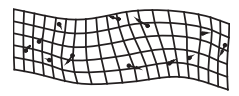

12.89

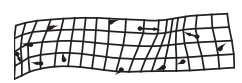

12.40
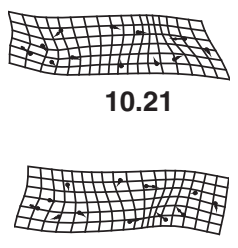

10.51
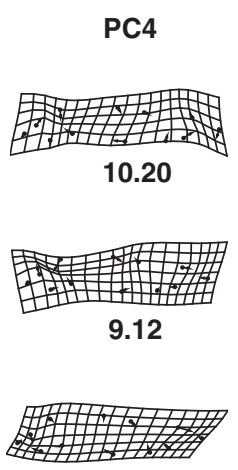

10.15

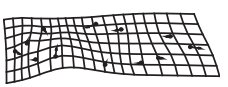

9.27
Fig. 6. The structure of variation for each size sample of brook charr from (A) lake and (B) stream. Shown are the four principal components (PCs) of variation for shape variables after removing bending and allometry. Each PC is depicted as a combination of the deformed grid and vectors of relative displacements of landmarks. Size range of each sample is indicated on the left; the percentage of variation explained by each $\mathrm{PC}$ is indicated below. 
Table 3. Differences in structure of variation, measured by the angle (in degrees) between the subspaces encompassing $80 \%$ of the variation: (A) for successive size classes within habitat, $(B)$ from the smallest size class $(<20 \mathrm{~mm})$ within habitat and $(C)$ between lake and stream samples

\begin{tabular}{|c|c|c|c|c|}
\hline Size classes & $\begin{array}{l}\text { Number } \\
\text { of PCs }\end{array}$ & $\mathrm{B}$ & $W(1)$ & $W(2)$ \\
\hline \multicolumn{5}{|l|}{$(A)$} \\
\hline \multicolumn{5}{|l|}{ Lake } \\
\hline$<20$ to $20-25 \mathrm{~mm}$ & 8 & 60.05 & 107.58 & 94.79 \\
\hline $20-25$ to $25-30 \mathrm{~mm}$ & 8 & 73.12 & 89.92 & 98.03 \\
\hline $25-30$ to $30-35 \mathrm{~mm}$ & 7 & 92.08 & 101.88 & 108.74 \\
\hline $30-35$ to $35-40 \mathrm{~mm}$ & 7 & 107.31 & 106.47 & 110.27 \\
\hline $35-40$ to $>40 \mathrm{~mm}$ & 6 & 91.52 & 101.9 & 116.46 \\
\hline \multicolumn{5}{|l|}{ Stream } \\
\hline$<20$ to $20-25 \mathrm{~mm}$ & 8 & 109.14 & 114.96 & 112.74 \\
\hline $20-25$ to $25-30 \mathrm{~mm}$ & 8 & 102.41 & 98.87 & 97.35 \\
\hline $25-30$ to $30-35 \mathrm{~mm}$ & 8 & 84.63 & 93.04 & 104.25 \\
\hline $30-35$ to $35-40 \mathrm{~mm}$ & 8 & 101.27 & 106.63 & 110.89 \\
\hline $35-40$ to $>40 \mathrm{~mm}$ & 7 & 79.56 & 110.97 & 106.59 \\
\hline \multicolumn{5}{|l|}{ (B) } \\
\hline \multicolumn{5}{|l|}{ Lake } \\
\hline $20-25 \mathrm{~mm}$ & 8 & 60.05 & 107.58 & 94.79 \\
\hline $25-30 \mathrm{~mm}$ & 8 & 107.82 & 109.54 & 106.73 \\
\hline $30-35 \mathrm{~mm}$ & 8 & 127.73 & 108.14 & 117.07 \\
\hline $35-40 \mathrm{~mm}$ & 8 & 122.05 & 108.31 & 112.53 \\
\hline$>40 \mathrm{~mm}$ & 8 & 126.02 & 108.86 & 132.83 \\
\hline \multicolumn{5}{|l|}{ Stream } \\
\hline $20-25 \mathrm{~mm}$ & 8 & 109.14 & 114.96 & 112.74 \\
\hline $25-30 \mathrm{~mm}$ & 8 & 124.04 & 125.57 & 120.14 \\
\hline $30-35 \mathrm{~mm}$ & 8 & 110.04 & 123.33 & 120.35 \\
\hline $35-40 \mathrm{~mm}$ & 8 & 139.51 & 121.55 & 119.51 \\
\hline$>40 \mathrm{~mm}$ & 8 & 137.07 & 124.65 & 121.13 \\
\hline \multicolumn{5}{|l|}{ (C) } \\
\hline$<20 \mathrm{~mm}$ & 8 & 136.46 & 100.50 & 117.65 \\
\hline $20-25 \mathrm{~mm}$ & 8 & 111.10 & 85.94 & 99.58 \\
\hline $25-30 \mathrm{~mm}$ & 8 & 109.03 & 98.58 & 96.87 \\
\hline $30-35 \mathrm{~mm}$ & 8 & 93.80 & 104.26 & 106.17 \\
\hline $35-40 \mathrm{~mm}$ & 7 & 108.69 & 108.88 & 109.85 \\
\hline$>40 \mathrm{~mm}$ & 6 & 120.68 & 132.22 & 122.70 \\
\hline
\end{tabular}

Given are the number of principal components compared (No. of PCs), between-size angle $(B)$, within-size angles $[W(1) / W(2)]$. When $B$ exceeds both $W(1)$ and $W(2)$, the difference between the two subspaces is statistically significant (indicated in bold face).

variance of shape drastically decreases. The contrast between levels of variance and integration suggests a high degree of random variation, that is, variation that is independent from landmark to landmark.
Table 4. Random skewers and matrix disparity between covariance matrices. (A) for successive size classes within habitat, (B) between lake and stream samples

\begin{tabular}{|c|c|c|c|c|}
\hline & \multicolumn{2}{|c|}{ Lake } & \multicolumn{2}{|c|}{ Stream } \\
\hline & $R_{(\mathrm{rs})}$ & $M_{(\mathrm{d})}$ & $R_{(\mathrm{rs})}$ & $M_{(\mathrm{d})}$ \\
\hline \multicolumn{5}{|l|}{$(A)$} \\
\hline$<20$ to $20-25 \mathrm{~mm}$ & 0.89 & 0.47 & 0.76 & 0.59 \\
\hline $20-25$ to $25-30 \mathrm{~mm}$ & 0.90 & 0.39 & 0.80 & 0.43 \\
\hline $25-30$ to $30-35 \mathrm{~mm}$ & 0.78 & 0.52 & 0.86 & 0.29 \\
\hline $30-35$ to $35-40 \mathrm{~mm}$ & 0.70 & 0.54 & 0.85 & 0.32 \\
\hline \multirow[t]{2}{*}{$35-40$ to $>40 \mathrm{~mm}$} & 0.66 & 0.74 & 0.67 & 0.57 \\
\hline & \multicolumn{2}{|c|}{$R_{(\mathrm{rs})}$} & & $M_{(\mathrm{d})}$ \\
\hline \multicolumn{5}{|l|}{ (B) } \\
\hline$<20 \mathrm{~mm}$ & \multicolumn{2}{|c|}{0.60} & & 0.87 \\
\hline $20-25 \mathrm{~mm}$ & \multicolumn{2}{|c|}{0.68} & & 0.67 \\
\hline $25-30 \mathrm{~mm}$ & \multicolumn{2}{|c|}{0.74} & & 0.59 \\
\hline $30-35 \mathrm{~mm}$ & \multicolumn{2}{|c|}{0.63} & & 0.53 \\
\hline $35-40 \mathrm{~mm}$ & \multicolumn{2}{|c|}{0.67} & & 0.56 \\
\hline$>40 \mathrm{~mm}$ & \multicolumn{2}{|c|}{0.49} & & 0.89 \\
\hline
\end{tabular}

For each sample, we present the average random skewers vector correlation $\left[R_{(\mathrm{rs})}\right]$ and the matrix disparity coefficient $\left[M_{(\mathrm{d})}\right]$, multiplied $1000-$ fold.

In both habitats, an abrupt decrease in number of newly ossified endoskeletal elements occurs when yearlings reach 25 $30 \mathrm{~mm}$ in SL and marks the beginning of the juvenile period. From this point on, the rate of change in body shape diminishes, the overall level of integration increases, and shape variance stabilizes. Consequently, the transition between alevin and juvenile coincides with changes in habitat, morphology, and function (Balon 1999; Kováć 2002), as well as with a shift between periods defined by level and structure of variance and integration.

\section{The general trends in variance and integration are common to populations from both habitats, but they do undergo different ontogenetic changes}

First, over ontogeny, stream fishes develop a deeper body with longer dorsal and anal fin bases, a more compressed caudal peduncle and fins that ossify at a significantly smaller size compared with lake fishes. Experimentally, higher water velocities generate earlier ossification of endoskeletal elements of the median fins in Arctic charrs (R. Cloutier, unpublished data) and a deeper body in various salmonids (Pakkasmaa and Piironen 2001; Imre et al. 2002; Peres-Neto and Magnan 2004; Fischer-Rousseau et al. in press). Second, our analysis 
suggests that lake fish tend to be more highly integrated than the ones from the stream habitat (i.e., 20-25, 25-30, and 30 $35 \mathrm{~mm})$. The majority of our stream specimens $(72 \%)$ were caught at water velocities faster than 1.0 body length per second, corresponding roughly to the "fast" treatment which generated the lowest integration level in Peres-Neto and Magnan (2004). The lower integration found in our fish from the stream habitat thus agrees with previous results. Because the differences we observe between lake and stream fishes could represent either adaptations or plastic responses to environmental conditions (i.e., water velocity), these differences will be put aside to concentrate on the one ontogenetic pattern common to both habitats.

\section{Developmental rate could contribute to the ontogenetic pattern observed for variance and integration}

There is a transition from high and largely random variation during the free-embryo period to the lower and more integrated variation seen in juveniles. High developmental rates in free-embryos, evident from important shape changes, and rapid ossification, could result in greater variation in degree of maturity within the smaller size classes, which is expected to result in high variance and low integration. As development slows down and individuals all eventually reach a similar state, maturity is expected to become less variable. As we observe, this should diminish variance while increasing integration. This hypothesis of ontogenetic decrease in developmental rate has been proposed to explain how variation in skull shape could decrease even as fluctuating asymmetry increases (Hallgrímsson 1999) and also makes sense in the context of fish development.

The ossification of the axial skeleton, transition from embryonic to juvenile/adult muscle, and the acquisition of adult body shape are all thought to be related developmental events, linked to the transition to exogenous feeding that occurs at the beginning of the alevin period (Koumans and Akster 1995). Accordingly, the intense development of both the muscular and the skeletal systems could produce the dominant changes in shape as well as high variation among individuals in degree of maturity. Diminishing variation in degree of maturity, however, would not explain why variation and integration both briefly diminish early in development, a pattern that suggests an increase in the randomness of variation even as variation itself diminishes. According to the palimpsest model proposed by Hallgrímsson et al. (2007), developmental processes are (co)variance generating, and the structure imparted by one process may be overwritten and obscured by others. The fact that the structure of covariation gradually changes within each habitat suggests that variation appears to be more random in structure because of the interaction between covariance generating processes.

\section{Variance and integration could be influenced by epigenetic interactions}

Following the initial reduction in variance, and in integration as well, variation remains stable and becomes less random (i.e., integration increases). Such changes need not be due only to passive mechanisms, such as the fact that all individuals eventually mature. These changes could also be due to mechanisms that preferentially eliminate random variation. Among the possibilities are cartilage and bone morphogenesis, muscle and bone interactions, and somatic growth. Most interesting are the epigenetic interactions between functioning muscles and the skeleton, which would lead locomotion and feeding to contribute to the loss of random variation. Such interactions have been invoked to explain ontogenetic changes in vertebrate skull shape (e.g., Moss 1997a,b,c,d), the decrease in variance of skull shape in mammals (Zelditch et al. 2004) as well as the development towards the adult patterns of integration before weaning in rodents (Zelditch 1987, 1988; Willmore et al. 2006; Zelditch et al. 2006). Whether the epigenetic influence of locomotion and feeding can explain differences in variance of body shape in fish is unknown but function is usually thought to be responsible for changes in phenotypic responses (Imre et al. 2001, 2002; Pakkasmaa and Piironen 2001; Grünbaum et al. 2007, 2008), including morphological integration in salmonids (Peres-Neto and Magnan 2004) and sunfishes (L. gibbosus) (Parsons and Robinson 2006). The gradual elimination of the initial variation in degree of maturity could allow for the epigenetic effects of locomotion and feeding to become apparent and later increase the covariation among functionally related traits (i.e., increase in level of integration).

\section{The juvenile covariation structure appears to arise from the sequential overlay of many developmental processes}

The ontogenetic stability of covariance structure seen in postweaning rodent skulls (Zelditch 1987, 1988; Willmore et al. 2006; Zelditch et al. 2006) or postnatal primate scapulae (Young 2006) is not characteristic of either of these two ecologically distinct populations of brook charrs. In these studies, integration and variance are measured at grossly different scales (i.e., skull or scapular shape vs. overall body shape), and the developmental stages are not equivalent (i.e., postnatal or postweaning mammalian development vs. posthatch development in teleosts). Nevertheless, in these brook charr, the structure of variation does not appear to retain the imprint of earlier ontogeny as it does in mammalian skulls and scapulae. Consequently, adult mouse skulls might be appropriate models to determine potential causes of variability (Willmore et al. 2006) but the dynamic nature of variability in body shape would make juveniles, and perhaps adult fishes, less reliable guides to the earlier causes of variability. The 
juvenile covariation structure of these teleosts appears to arise from the sequential overlay of many developmental processes, highlighting the difficulty of inferring the developmental, and functional causes of integration from studies of static covariance structures (Hallgrímsson et al. 2007).

\section{CONCLUSION}

The fact that we find one ontogenetic pattern common to both habitats suggests a stability of processes responsible for the complex dynamics of integration and variance. We have isolated a novel and complex ontogenetic pattern of integration that is linked to the alevin-juvenile transition but this is only a first step in further understanding how developmental processes are responsible for the changes in covariance seen during fish ontogeny. To better understand these ontogenetic changes in covariance and further explain small evolutionary changes occurring between populations or species, we will likely need to combine data from functional morphology and developmental biology. In this respect, fishes represent a promising model system as water velocity is a common, effective, and noninvasive way to alter functional demands and impose elevated, but physiologically normal mechanical loads on the developing musculoskeletal system.

\section{REFERENCES}

Ackermann, R. R., and Cheverud, J. M. 2002. Discerning evolutionary processes in patterns of tamarin (genus Saguinus) craniofacial variation. Am. J. Phys. Anthropol. 117: 260-271.

Adriaens, D., and Verraes, W. 2002. An empirical approach to study the relation between ontogeny, size and shape using geometric morphometrics. In P. Aert, C. D'Août, A. Herrel, and R. Van Damme (eds.). Topics in Functional and Ecological Vertebrate Morphology. Shaker Publishing, Maastricht, pp. 293-324.

Anderson, T. W. 1963. Asymptotic theory for principal components. Ann. Math. Stat. 34: 122-148.

Atchley, R., and Rutledge, J. J. 1980. Genetic components of size and shape. I. Dynamic components of phenotypic variability and covariability in the laboratory rat. Evolution 35: 1161-1173.

Badyaev, A. V., and Martin, T. E. 2000. Individual variation in growth trajectories: phenotypic and genetic correlations in ontogeny of the house finch (Carpodacus mexicanus). J. Evol. Biol. 13: 290-301.

Balon, E. K. 1980. Early ontogeny of the brook charr, Salvelinus (Baione) fontinalis. In E. K. Balon (ed.). Charrs: Salmonids of the Genus Salvelinus. Kluwer Boston Inc., Hingham, pp. 631-666.

Balon, E. K. 1999. Alternative ways to become a juvenile or a definitive phenotype (and on some persisting linguistic offenses). Environ. Biol. Fishes 56: 17-38.

Cheverud, J. M. 1982. Phenotypic, genetic and environmental integration in the cranium. Evolution 36: 499-512.

Cheverud, J. M. 1996. Quantitative genetic analysis of cranial morphology in the cotton-top (Saguinus oedipus) and saddle-back (S. fuscicollis) tamarins. J. Evol. Biol. 9: 5-42.

Dingerkus, G., and Uhler, L. D. 1977. Enzyme clearing of Alcian blue stained whole small vertebrates for demonstrating cartilage. Stain Tech. 56: $271-273$.

Fischer-Rousseau, L., Chu, K. P., and Cloutier, R. In press. Developmental plasticity in fish exposed to a water velocity gradient: a complex response. J. Exp. Zool. (Mol. Dev. Evol.).
Flury, B. 1988. Common Principal Components and Related Multivariate Models. Wiley, New York, 258pp.

Gisbert, E. 1999. Early development and allometric growth patterns in Siberian sturgeon and their ecological significance. J. Fish Biol. 54: 852862.

Goodall, C. 1991. Procrustes methods in the statistical analysis of shape. $J$. Roy. Stat. Soc. Ser. B. (Stat. Meth.) 53: 285-339.

Grünbaum, T., Cloutier, R., and Le François, N. R. 2008. Positive effects of exposure to increased water velocity on growth of newly-hatched Arctic charr, Salvelinus alpinus L. Aquac. Res. 39: 106-110.

Grünbaum, T., Cloutier, R., Mabee, P. M., and Le François, N. R. 2007. Early developmental plasticity and integrative responses in Arctic charr (Salvelinus alpinus): effects of water velocity on body size and shape. $J$. Exp. Zool. (Mol. Dev. Evol.) 308B: 396-408.

Hallgrímsson, B. 1999. Ontogenetic patterning of skeletal fluctuating asymmetry in rhesus macaques and humans: evolutionary and developmental implications. Int. J. Primatol. 20: 121-151.

Hallgrímsson, B., Lieberman, D. E., Liua, W., Ford-Hutchínsonc, A. F. and Jirikc, F. R. 2007. Evolution of covariance in the mammalian skull. In G. Bock and J. Goode (eds.). Tinkering: the Microevolution of Development (Novartis Foundation Symposium 284). Wiley, Chichester, pp. 164-190.

Hendrikse, J. L., Parsons, T. E., and Hallgrímsson, B. 2007. Evolvability as the proper focus of evolutionary developmental biology. Evol. Dev. 9: 393-401

Imre, I., McLaughlin, R. L., and Noakes, D. L. G. 2001. Temporal persistence of resource polymorphism in Brook charr, Salvelinus fontinalis. Environ. Biol. Fishes 60: 393-399.

Imre, I., McLaughlin, R. L., and Noakes, D. L. G. 2002. Phenotypic plasticity in Brook charr: changes in caudal fin induced by water flow. J. Fish Biol. 61: 1171-1181.

Ivanović, A., Kalezić, M. L., and Aleksić, I. 2005. Morphological integration of cranium and postcranial skeleton during ontogeny of facultative paedomorphic European newts (Triturus vulgaris and T. alpestris). Amphibia-Reptilia 26: 485-495.

Klingenberg, C. P., and McIntyre, G. S. 1998. Geometric morphometrics of developmental instability: analyzing patterns of fluctuating asymmetry with procrustes methods. Evolution 52: 1363-1375.

Koumans, J. T. M., and Akster, H. A. 1995. Myogenic cells in development and growth of fish. Comp. Biochem. Physiol. 110: 3-20.

Kováč, V. 2002. Synchrony and heterochrony in ontogeny (of fish). $J$. Theor. Biol. 217: 499-507.

Marroig, G., and Cheverud, J. M. 2001. A comparison of phenotypic variation and covariation patterns and the role of phylogeny, ecology, and ontogeny during cranial evolution of the new world monkeys. Evolution 55: 2576-2600.

Moss, M. L. 1997a. The functional matrix hypothesis revisited. 1. The role of mechanotransduction. Am. J. Orthod. Dentofac. Orthop. 112: 8-11.

Moss, M. L. 1997b. The functional matrix hypothesis revisited. 2. The role of an osseous connected cellular network. Am. J. Orthod. Dentofac. Orthop. 112: 221-226.

Moss, M. L. 1997c. The functional matrix hypothesis revisited. 3. The genomic thesis. Am. J. Orthod. Dentofac. Orthop. 112: 338-342.

Moss, M. L. 1997d. The functional matrix hypothesis revisited. 4. The epigenetic antithesis and the resolving synthesis. Am. J. Orthod. Dentofac. Orthop. 112: 410-417.

Olson, E. C., and Miller, R. L. 1958. Morphological Integration. University of Chicago Press, Chicago, $376 \mathrm{pp}$

Pakkasmaa, S., and Piironen, J. 2001. Water velocity shapes juvenile salmonids. Evol. Ecol. 14: 721-730.

Parsons, K. J., and Robinson, B. W. 2006. Replicated evolution of integrated plastic responses during early adaptive divergence. Evolution 60: 801-813.

Peres-Neto, P. R., and Magnan, P. 2004. The influence of swimming demand on phenotypic plasticity and morphological integration: a comparison of two polymorphic charr species. Oecologia 140: 36-45.

Proulx, R., and Magnan, P. 2004. Contribution of phenotypic plasticity and heredity to the trophic polymorphism of lacustrine brook charr (Salvelinus fontinalis M.). Evol. Ecol. Res. 6: 503-522. 
Quinn, G. P., and Keough, M. J. 2002. Experimental Design and Data Analysis for Biologists. Cambridge University Press, Cambridge, UK, 520pp.

R Development Core Team. 2005. R A Language and Environment for Statistical Computing. Vienna, Austria. http://www.r-project. org.

Riska, B. 1986. Some models for development, growth, and morphometric correlation. Evolution 40: 1303-1311.

Robinson, B. W., and Wilson, D. S. 1994. Character release and displacement in fishes: a neglected literature. Am. Nat. 144: 596-627.

Rohlf, F. J. 2000. Statistical power comparisons among alternative morphometric methods. Am. J. Phys. Anthropol. 111: 463-478.

Rohlf, F. J., and Slice, D. 1990. Extensions of the procrustes method for the optimal superimposition of landmarks. Syst. Zool. 39: 40-59.

Schlichting, C. D., and Pigliucci, M. 1998. Phenotypic Evolution: A Reaction Norm Perspective. Sinauer Associates, Sunderland, 387pp.

van Snik, G. M. J., van den Boogaart, J. G. M., and Osse, J. W. M. 1997. Larval growth patterns in Cyprinus carpio and Clarias gariepinus with attention to finfold. J. Fish Biol. 50: 1339-1352.

Venne, H., and Magnan, P. 1995. The impact of intra- and interspecific interactions on young-of-the-year brook charr, in temperate lakes. J. Fish Biol. 46: 669-686.

Wagner, G. P. 1984. On the eigenvalue distribution of genetic and phenotypic dispersion matrices - evidence for a non-random organization of quantitative character variation. J. Math. Biol. 21: 77-95.
Willmore, K. E., Leamy, L., and Hallgrímsson, B. 2006. Effects of developmental and functional interactions on mouse cranial variability through late ontogeny. Evol. Dev. 8: 550-567.

Wund, M. A., Baker, J. A., Clancy, B., Golub, J. L., and Foster, S. A. 2008. A test of the "flexible stem" model of evolution: ancestral plasticity, genetic accommodation, and morphological divergence in the threespine stickleback radiation. Am. Nat. 172: 449-462.

Young, N. M. 2006. Function, ontogeny and canalization of shape variance in the primate scapula. J. Anat. 209: 623-636.

Zelditch, M. L. 1987. Evaluating models of developmental integration in the laboratory rat using confirmatory factor analysis. Syst. Zool. 36 368-380.

Zelditch, M. L. 1988. Ontogenetic variation in patterns of phenotypic integration in the laboratory rat. Evolution 42: 28-41.

Zelditch, M. L., and Carmichael, A. C. 1989. Ontogenetic variation in patterns of developmental and functional integratrion in skulls of Sigmodon fulviventer. Evolution 43: 814-824.

Zelditch, M. L., Lundrigan, B. L., and Garland, T. 2004. Developmental regulation of skull morphology. I. Ontogenetic dynamics of variance. Evol. Dev. 6: 194-206.

Zelditch, M. L., Mezey, J., Sheets, D. H., Lundrigan, B. L., and Garland, T. 2006. Developmental regulation of skull morphology II: ontogenetic dynamics of covariance. Evol. Dev. 8: 46-60. 